\title{
Unveiling the In Situ Generation of a Monovalent Fe(I) Site in the Single-Fe-Atom Catalyst for Electrochemical $\mathrm{CO}_{2}$ Reduction
}

Xuning Li, ${ }^{\dagger \neq}$ Yaqiong Zeng, ${ }^{\ddagger}$ Ching-Wei Tung, ${ }^{\S}$ Ying-Rui Lu,, Sambath Baskaran, ${ }^{\perp}$ Shifu Wang, Sung-Fu Hung, ${ }^{\S}$ Cong-Qiao Xu, ${ }^{\perp, *}$ Junhu Wang, ${ }^{\#}$ Ting-Shan Chan, ${ }^{\prime}$ Haoming Chen, Jianchao Jiang," Qi Yu," Yanqiang Huang, ${ }^{\ddagger, *}$ Jun Li, ${ }^{\perp, \nabla}$ Tao Zhang, ${ }^{\ddagger}, \quad$ and Bin Liu ${ }^{\dagger, *}$

'School of Chemical and Biomedical Engineering, Nanyang Technological University, 62 Nanyang Drive, Singapore 637459, Singapore

'State Key Laboratory of Catalysis, Dalian Institute of Chemical Physics, Chinese Academy of Sciences, Dalian 116023, China

${ }^{\S}$ Department of Chemistry, National Taiwan University, Taipei 106, Taiwan

"National Synchrotron Radiation Research Center, Hsinchu 300, Taiwan

${ }^{\perp}$ Department of Chemistry, Southern University of Science and Technology, Shenzhen 518055, China

${ }^{\#}$ Mössbauer Effect Data Center, Dalian Institute of Chemical Physics, Chinese Academy of Sciences, Dalian 116023, China

"Shaanxi Key Laboratory of Catalysis, Shaanxi University of Technology, Hanzhong 723000, China DDepartment of Chemistry and Key Laboratory of Organic Optoelectronics \& Molecular Engineering of Ministry of Education, Tsinghua University, Beijing 100084, China

${ }^{\circ}$ University of Chinese Academy of Sciences, Beijing 100049, China
*Correspondence to: xucq@sustech.edu.cn
(C. Xu), yqhuang@dicp.ac.cn
(Y. Huang), and liubin@ntu.edu.sg (B. Liu). 


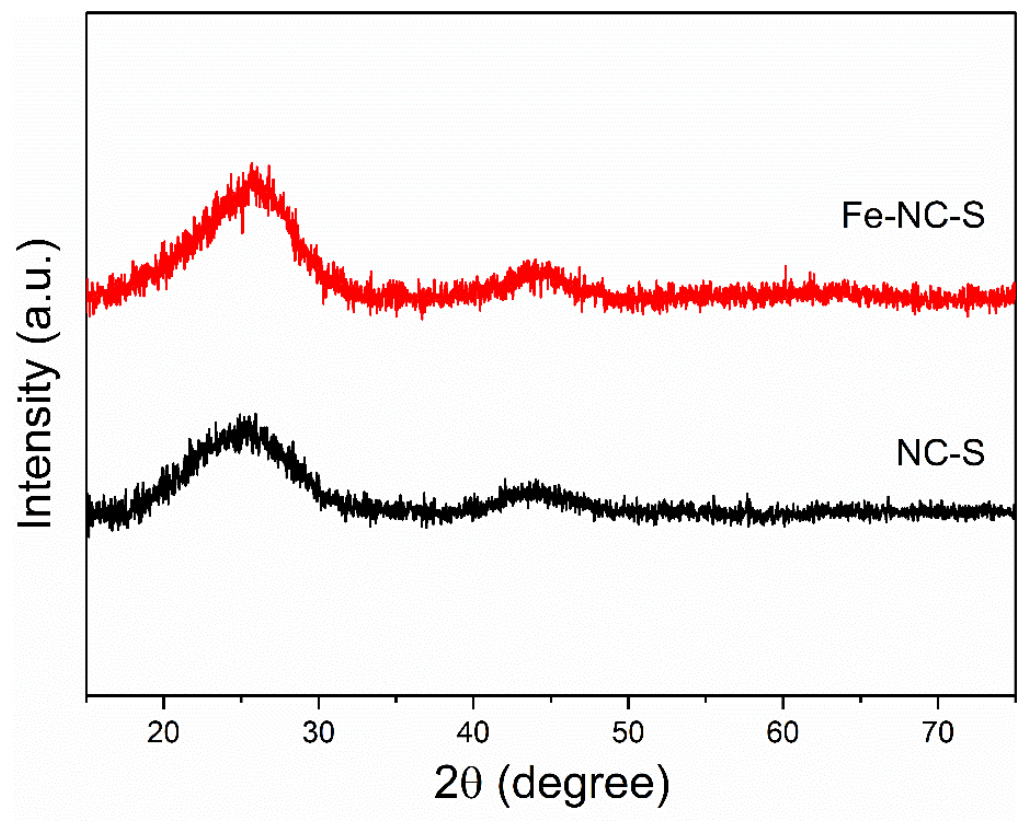

Figure S1. XRD patterns of Fe-NC-S and NC-S. 


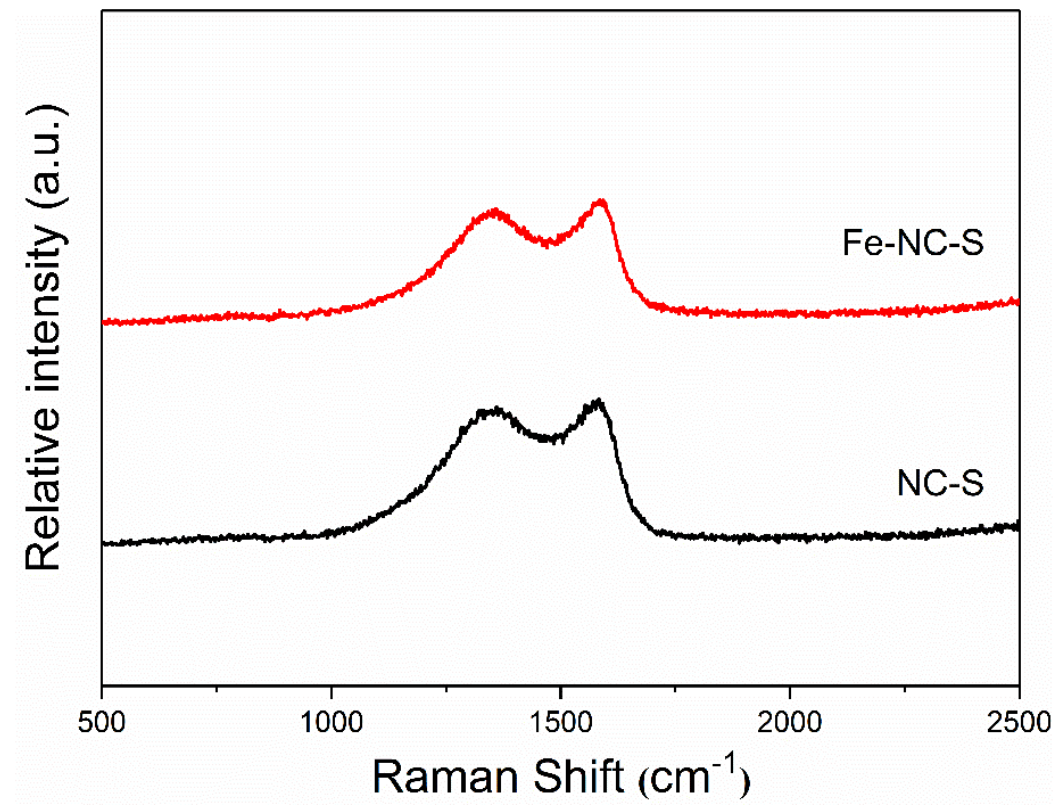

Figure S2. Raman spectra of Fe-NC-S and NC-S. 

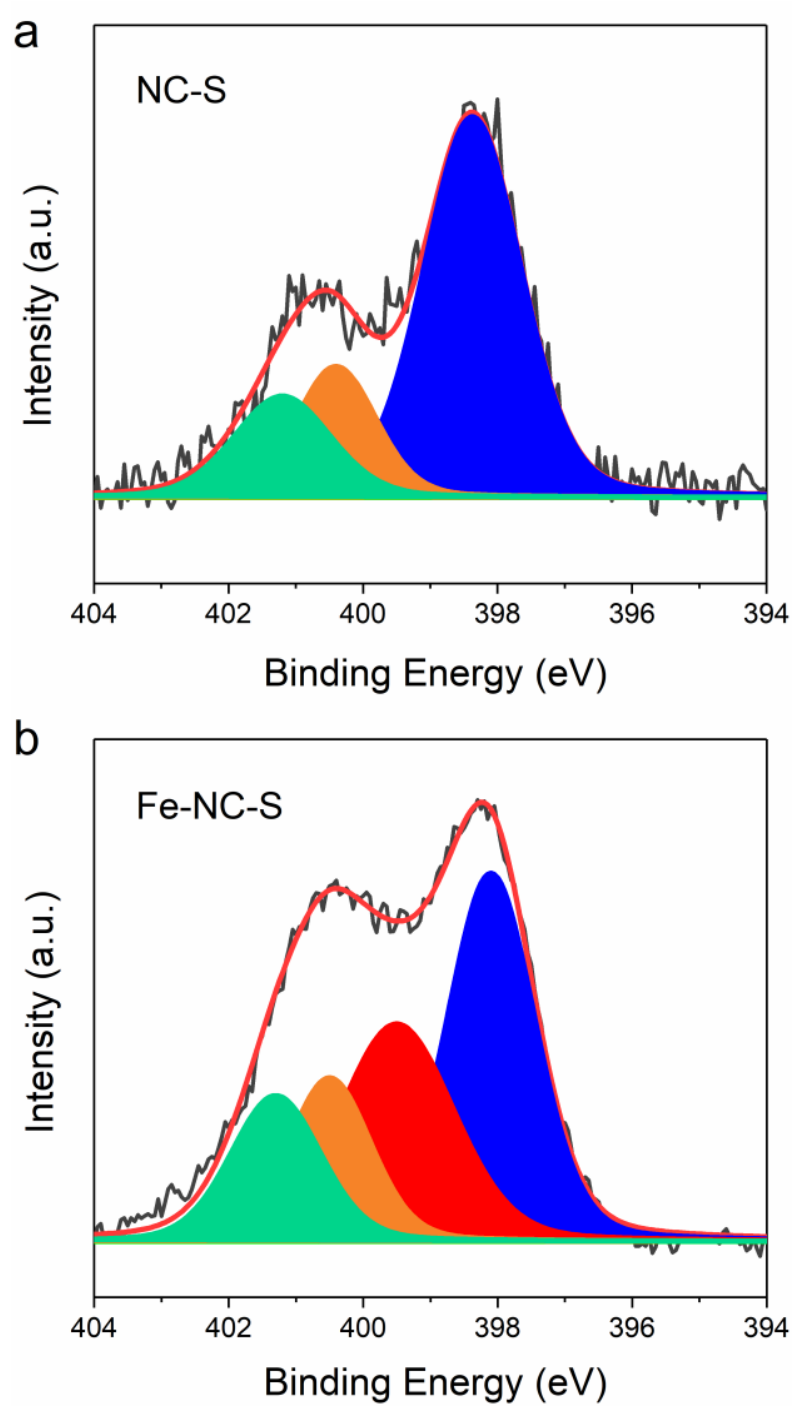

Figure S3. High-resolution XPS N 1s spectra of (a) NC-S and (b) Fe-NC-S. The spectra were fitted by three or four peaks with FWHM in the range from $1.5-2.0 \mathrm{eV}$ using the XPSPEAK41 software. The binding energies at 398.2, 399.5, 400.5, and $401.3 \mathrm{eV}$ could be assigned to pyridinic N, Fe-N, pyrrolic $\mathrm{N}$, and graphitic $\mathrm{N}$, respectively. ${ }^{1}$ 


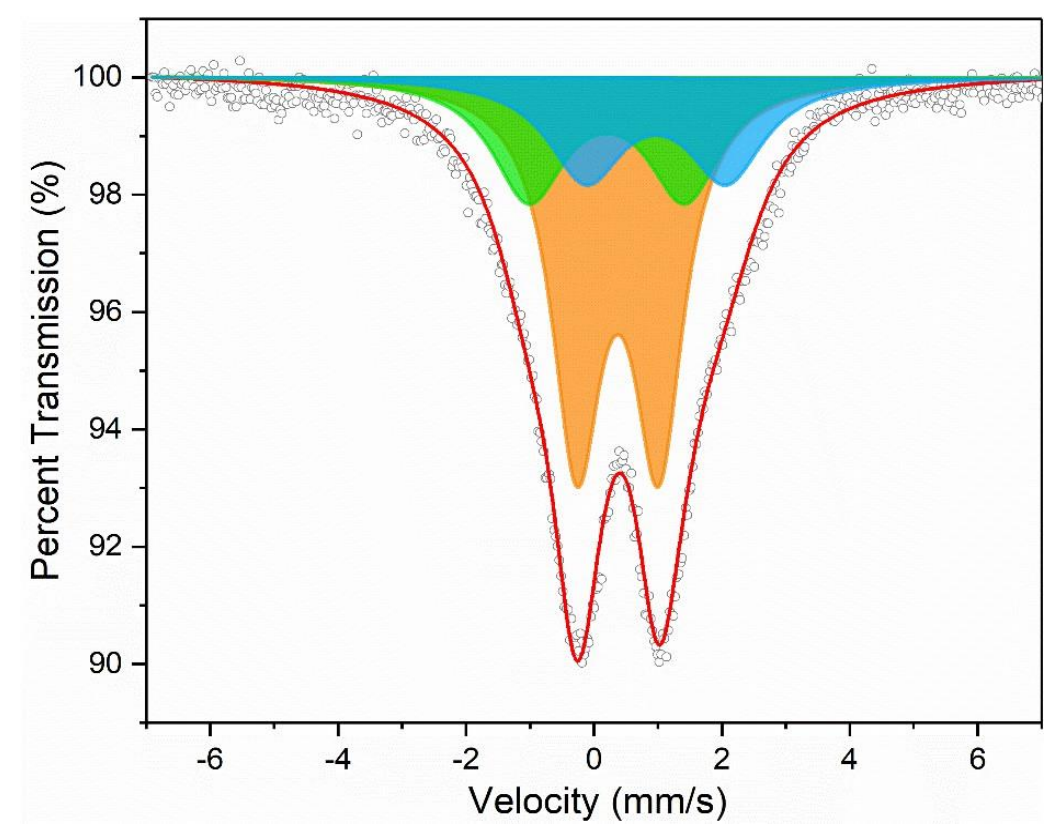

Figure S4. ${ }^{57} \mathrm{Fe}$ Mössbauer spectrum of ${ }^{57} \mathrm{Fe}$ enriched Fe-NC-S measured at $77 \mathrm{~K}$. As evidenced in our previous report, ${ }^{1}$ the absence of trivalent iron in Fe-NC-S was confirmed by spin-quantitated $2 \mathrm{~K}$ EPR, XPS, ${ }^{57} \mathrm{Fe}$ Mössbauer spectroscopy, in situ XAS results, as well as the Mössbauer parameters obtained from theoretical calculations. The NRVS results further excluded the potential existence of oxygen molecule bonded iron species. Therefore, in this work, the $77 \mathrm{~K}$ Mössbauer spectrum was fitted with three doublets accordingly. The orange, green, and blue doublets could be assigned to low-spin (LS) $\mathrm{Fe}^{2+}$ in $\mathrm{Fe}^{\mathrm{II}} \mathrm{N}_{4} \mathrm{C}_{12}$ (D1), intermediate spin (MS) $\mathrm{Fe}^{2+}$ in $\mathrm{Fe}^{\mathrm{II}} \mathrm{N}_{4} \mathrm{C}_{10}$ (D2), and high-spin (HS) $\mathrm{Fe}^{2+}$ in $\mathrm{N}-\mathrm{Fe}^{\mathrm{II}} \mathrm{N}_{4} \mathrm{C}_{10}$ (D3), respectively. 


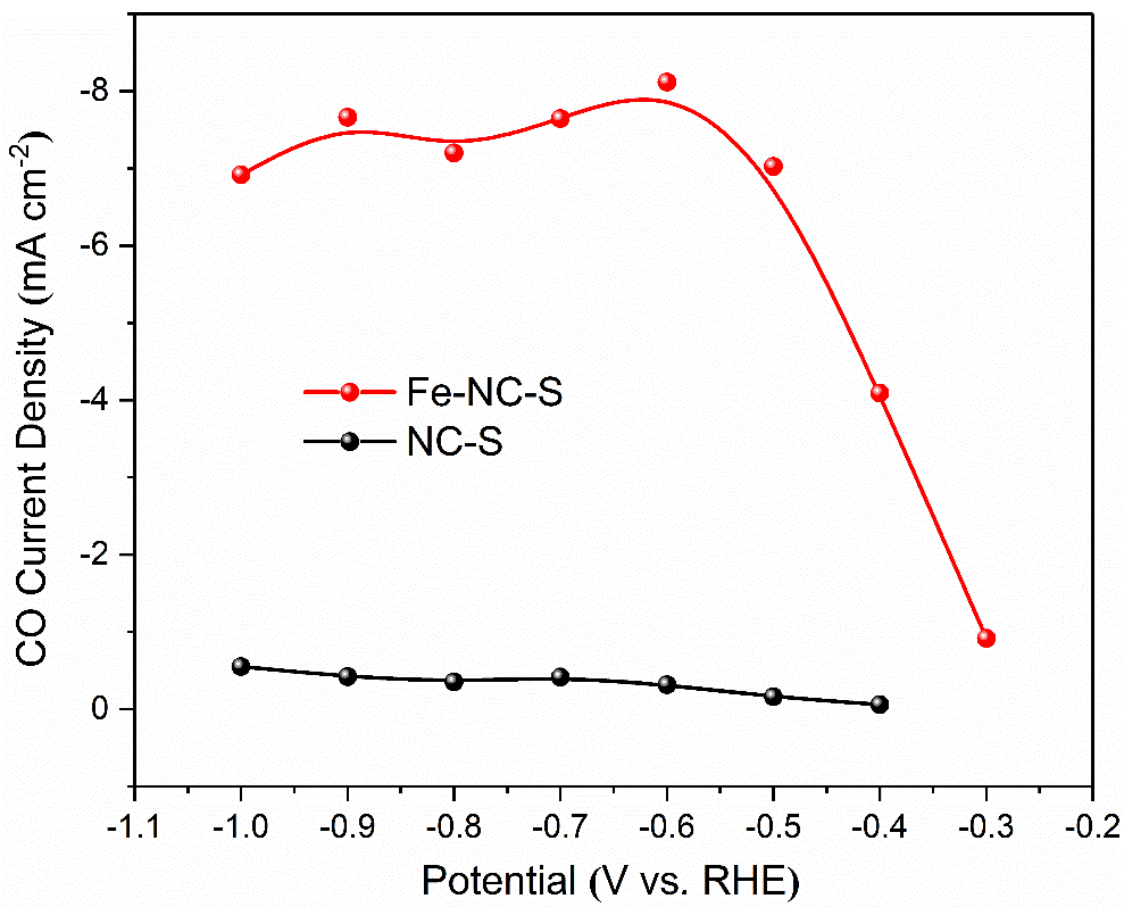

Figure S5. Partial current densities of $\mathrm{CO}$ for Fe-NC-S and NC-S at different potentials in $\mathrm{CO}_{2}$-saturated $0.5 \mathrm{M} \mathrm{KHCO}_{3}$ solution. 


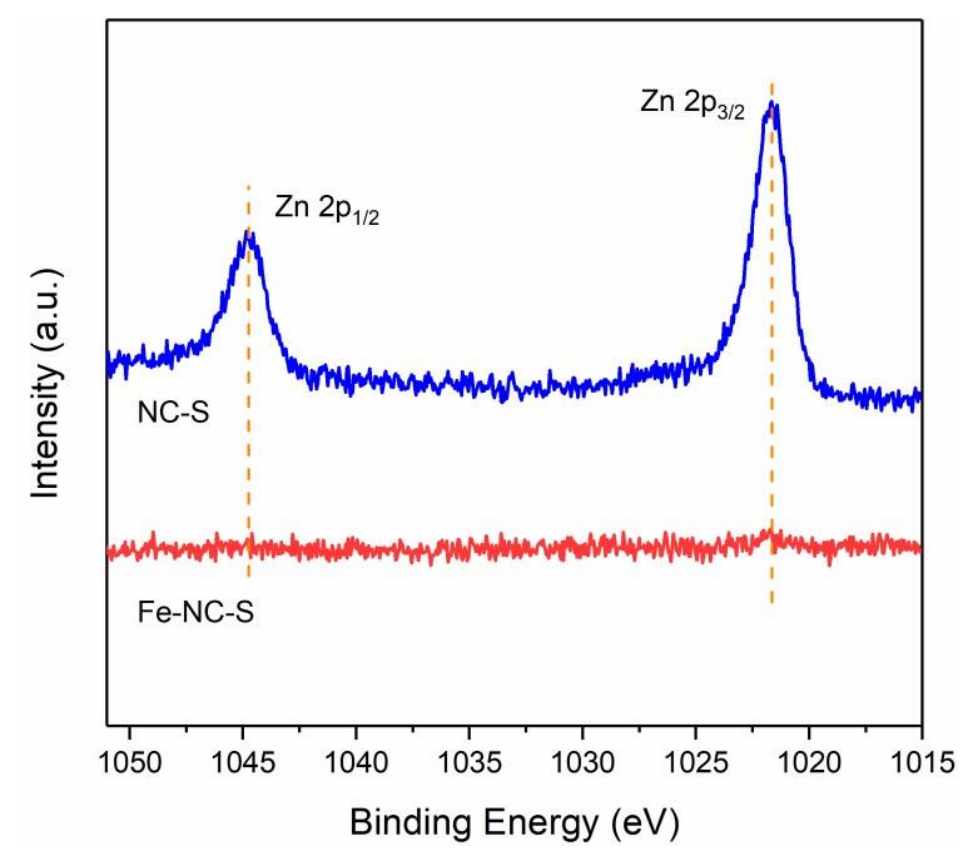

Figure S6. High-resolution XPS Zn 2p spectra of (a) NC-S and (b) Fe-NC-S. As shown, the content of $\mathrm{Zn}$ in the as-prepared single-Fe-atom catalyst is negligible compared to that in the NC-S, which clearly excludes the influence of $\mathrm{Zn}$ as the critical role for the largely improved catalytic performance towards the $\mathrm{CO}_{2} \mathrm{RR}$. 


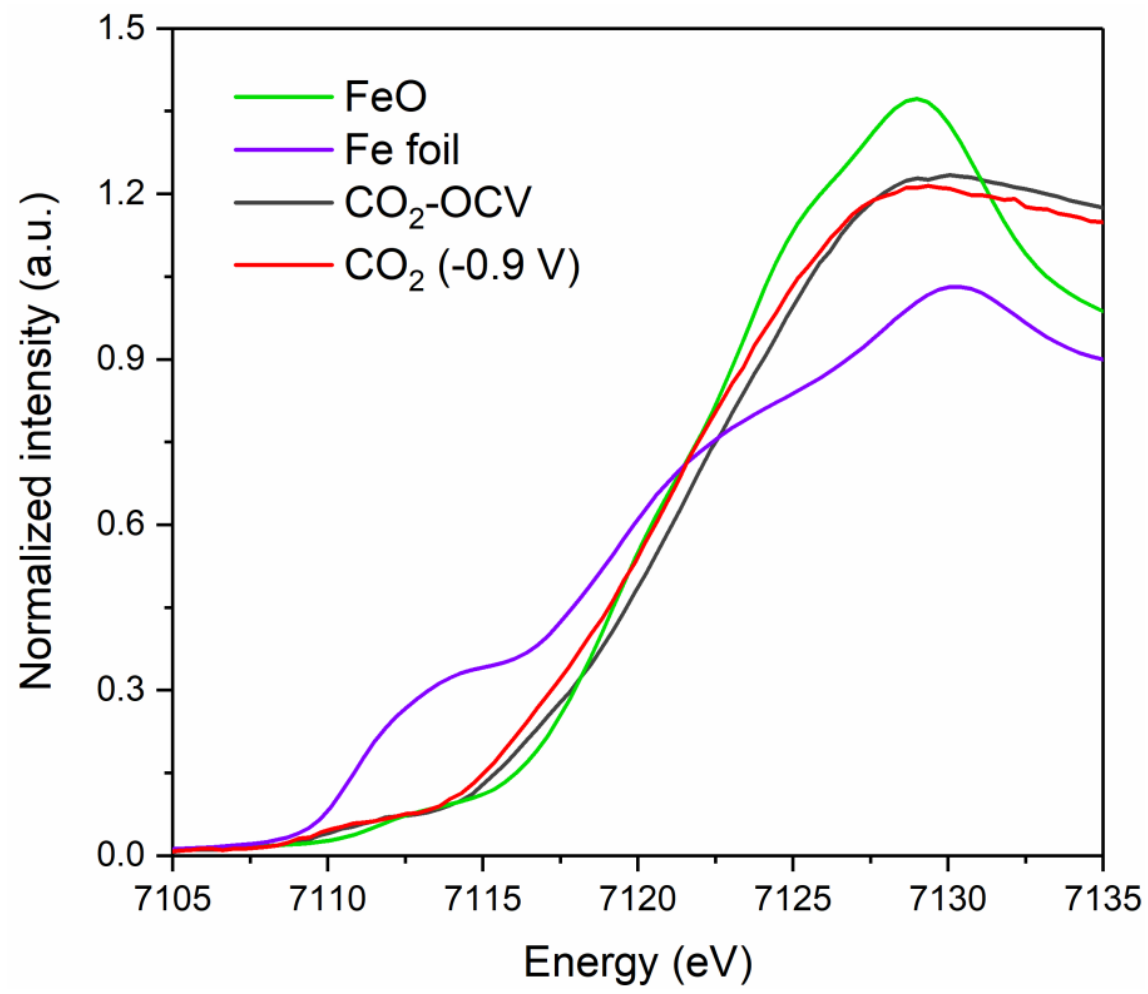

Figure S7. Fe K-edge XANES spectra of FeO, Fe foil, Fe-NC-S loaded on CP electrode recorded at OCV and $-0.9 \mathrm{~V}$ vs. RHE in $\mathrm{CO}_{2}$-saturated $0.5 \mathrm{M} \mathrm{KHCO}_{3}$ solution. 

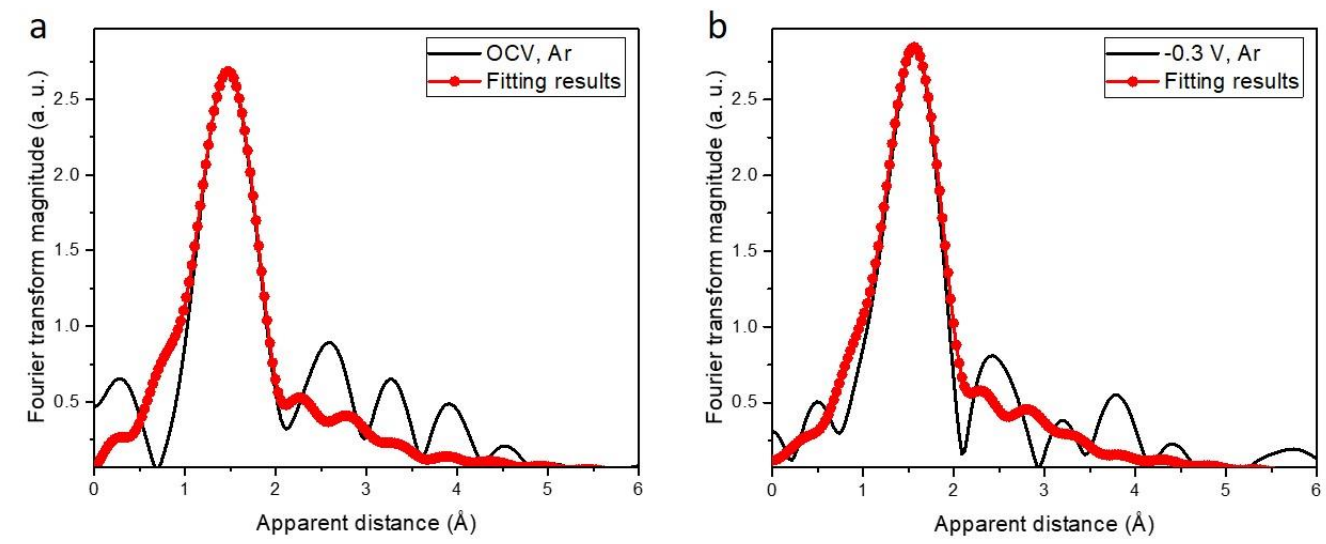

Figure S8. Fitting of $k^{3}$ weighted Fe K-edge EXAFS for Fe-NC-S recorded in Ar-saturated condition.

The k-range and R-range for the $k^{3}$-weighted Fe $K$-edge EXAFS are 2.5-10 $\AA^{-1}$ and 0-6 $\AA$, respectively. 

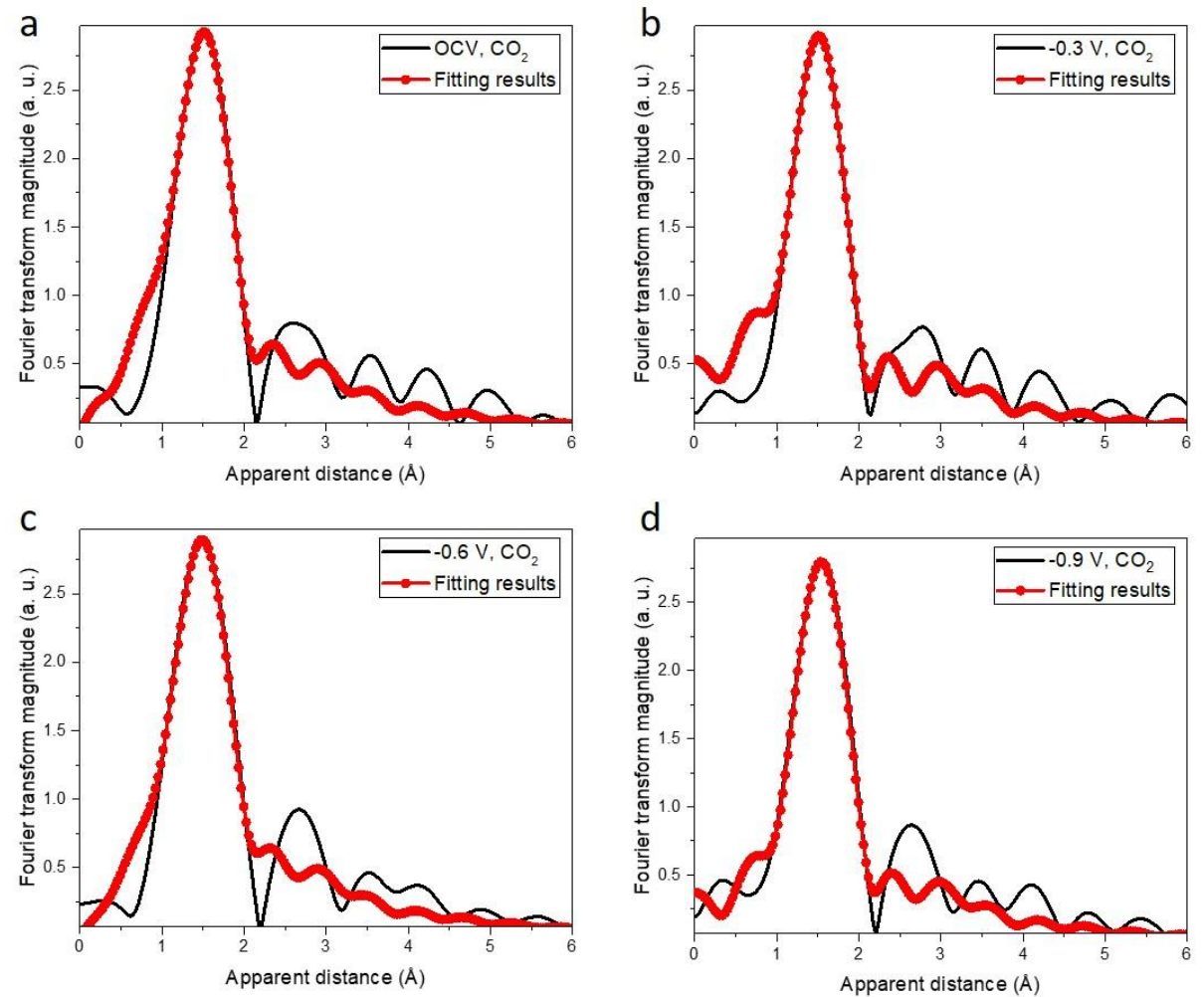

Figure S9. Fitting of $k^{3}$ weighted Fe K-edge EXAFS for Fe-NC-S recorded at various biases (vs. RHE) in $\mathrm{CO}_{2}$-saturated $0.5 \mathrm{M} \mathrm{KHCO}_{3}$ solution. The k-range and R-range for the $k^{3}$-weighted $\mathrm{Fe}$ $K$-edge EXAFS are 2.5-10 $\AA^{-1}$ and 0-6 $\AA$, respectively. 

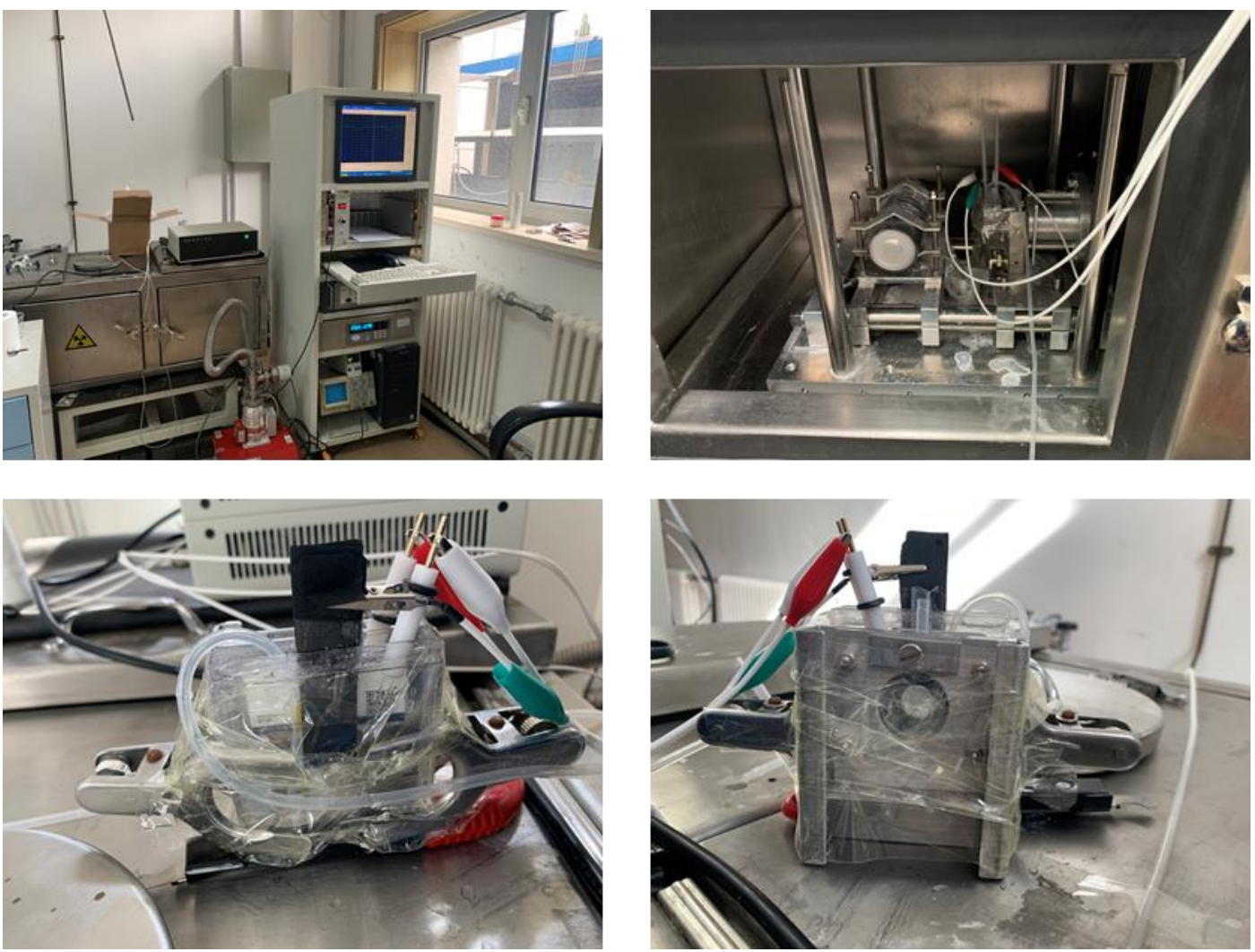

Figure S10. Photographs of the operando ${ }^{57} \mathrm{Fe}$ Mössbauer-electrochemical apparatus with home-made H-type cell. 

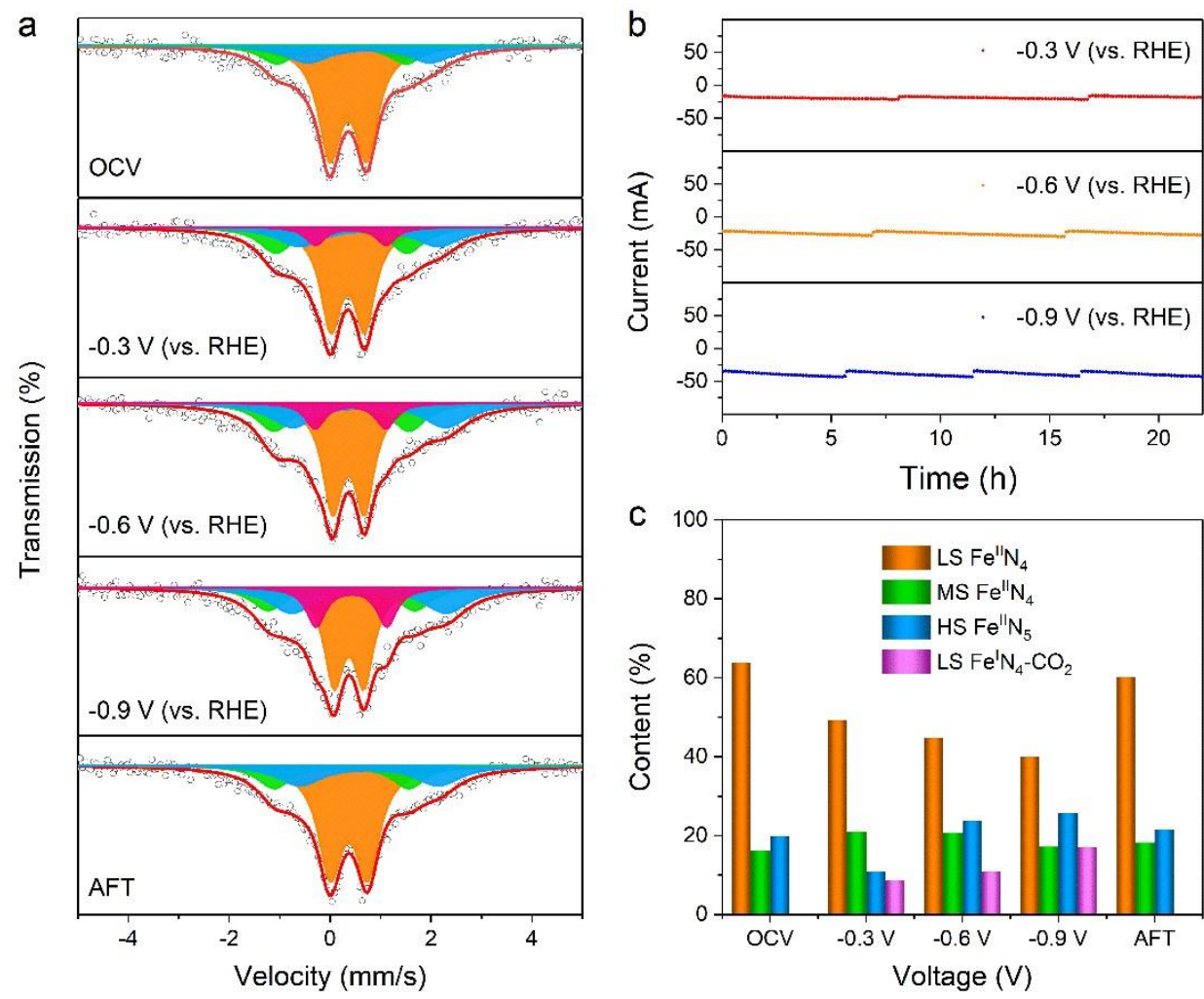

Figure S11. Operando ${ }^{57} \mathrm{Fe}$ Mössbauer characterization. (a) Operando ${ }^{57} \mathrm{Fe}$ Mössbauer spectra of ${ }^{57} \mathrm{Fe}$ enriched Fe-NC-S recorded at OCV, $-0.3 \mathrm{~V},-0.6 \mathrm{~V},-0.9 \mathrm{~V}$ (vs, RHE), and after CRR (AFT) in $\mathrm{CO}_{2}$-saturated $0.5 \mathrm{M} \mathrm{KHCO}_{3}$ solution. (b) Current-time response of ${ }^{57} \mathrm{Fe}$ enriched $\mathrm{Fe}-\mathrm{NC}-\mathrm{S}$ for CRR (the electrolyte of $\mathrm{CO}_{2}$-saturated $0.5 \mathrm{M} \mathrm{KHCO}_{3}$ was exchanged at every certain time interval to maintain the $\mathrm{pH}$ of the solution), and (c) Content of different Fe moieties and reactive intermediates obtained from operando ${ }^{57} \mathrm{Fe}$ Mössbauer measurements in $\mathrm{CO}_{2}$-saturated $0.5 \mathrm{M} \mathrm{KHCO}_{3}$ solution. 

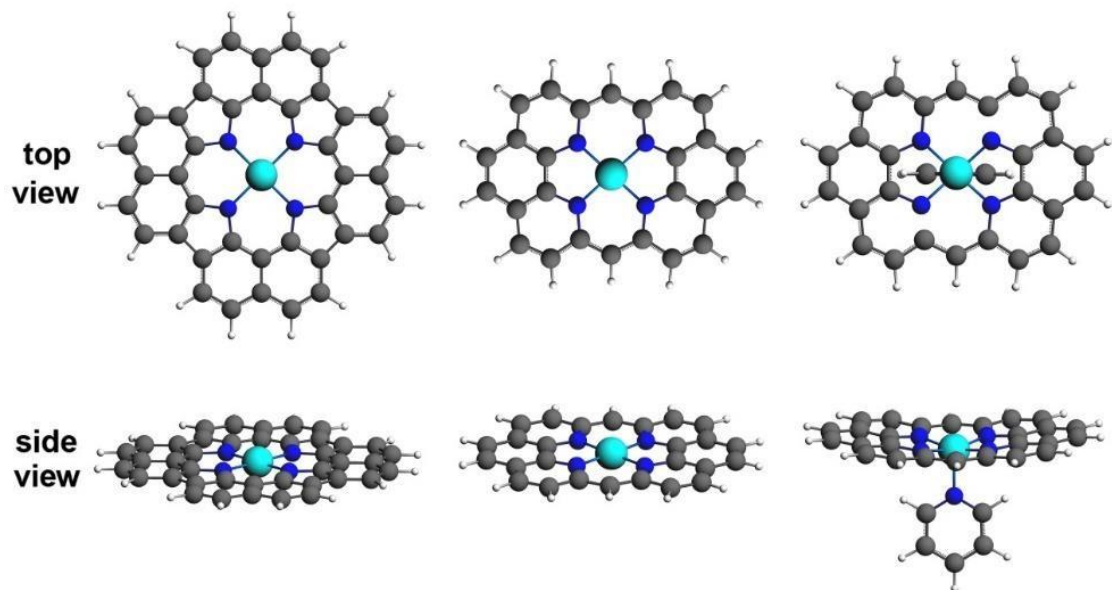

D1

D2

D3

Figure S12. Top views and side views of the model structures for the computationally optimized D1,

D2 and D3 moieties. Color code: cyan, Fe; blue, N; gray, C; white, H. 

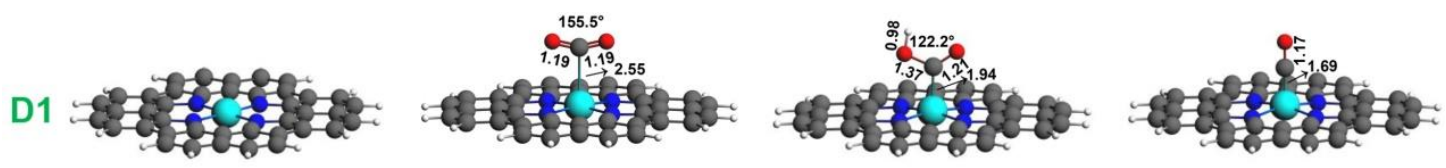

D2

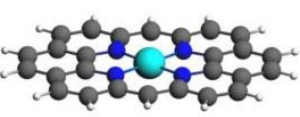

New Fe-C
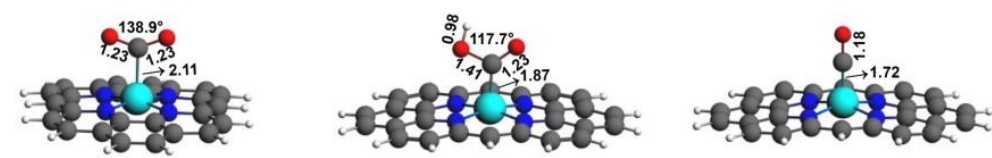

D3
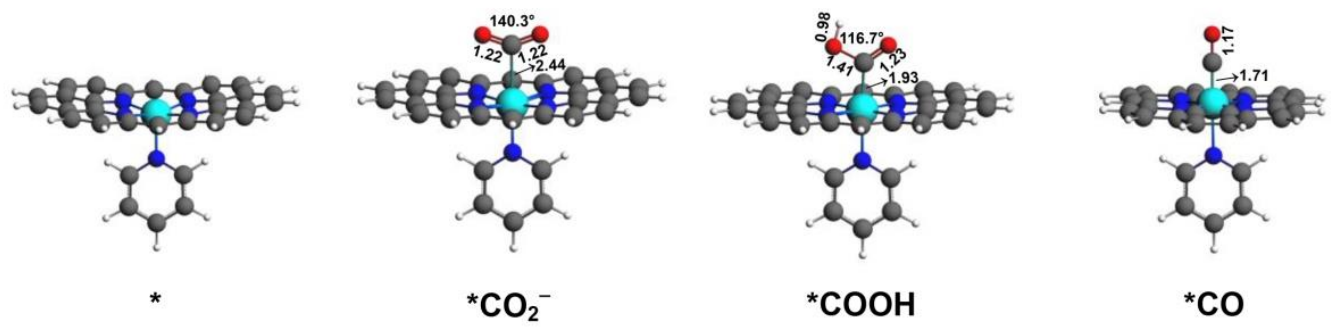

Figure S13. Optimized structures with selected structural parameters for the relevant intermediates in the CRR mechanism of D1, D2 and D3 moieties. Color code: cyan, Fe; blue, N; gray, C; red, O; white, $\mathrm{H}$. 


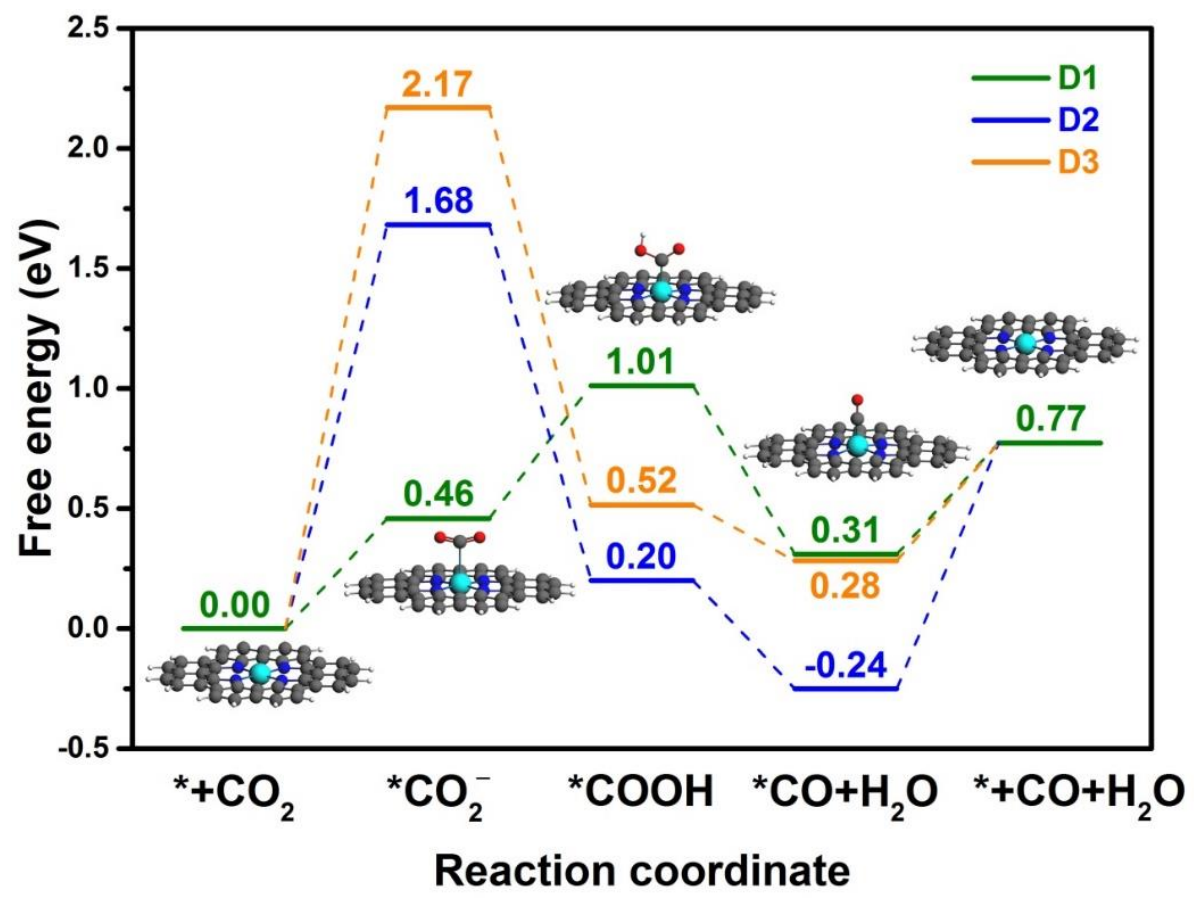

Figure S14. Gibbs free energy profiles for the CRR over D1, D2 and D3 moieties at U = 0 V. 
Table S1. Structural parameters obtained from the fitting results of the operando EXAFS spectra recorded at various applied biases in $\mathrm{Ar}$ or $\mathrm{CO}_{2}$-saturated $0.5 \mathrm{M} \mathrm{KHCO}_{3}$ solution.

\begin{tabular}{ccccc}
\hline Condition & Path & Coordination number & R (̊̊) & DW \\
\hline Dry & Fe-N & $3.89(1)$ & $1.97(1)$ & $0.092(1)$ \\
\hline $\mathrm{Ar}(\mathrm{OCV})$ & $\mathrm{Fe}-\mathrm{N}$ & $3.86(1)$ & $2.04(1)$ & $0.082(1)$ \\
\hline $\mathrm{Ar}(-0.3 \mathrm{~V})$ & $\mathrm{Fe}-\mathrm{N}$ & $3.90(1)$ & $2.09(1)$ & $0.046(1)$ \\
\hline $\mathrm{CO}_{2}(\mathrm{OCV})$ & $\mathrm{Fe}-\mathrm{N}$ & $3.78(1)$ & $1.96(2)$ & $0.088(1)$ \\
& $\mathrm{Fe}-\mathrm{C}$ & $0.19(1)$ & $1.86(1)$ & $0.046(2)$ \\
\hline $\mathrm{CO}_{2}(-0.3 \mathrm{~V})$ & $\mathrm{Fe}-\mathrm{N}$ & $3.80(2)$ & $2.01(1)$ & $0.090(2)$ \\
& $\mathrm{Fe}-\mathrm{C}$ & $0.35(2)$ & $1.88(1)$ & $0.046(1)$ \\
\hline $\mathrm{CO}_{2}(-0.9 \mathrm{~V})$ & $\mathrm{Fe}-\mathrm{N}$ & $3.79(2)$ & $1.99(1)$ & $0.090(1)$ \\
\hline & $\mathrm{Fe}-\mathrm{C}$ & $0.74(2)$ & $1.85(1)$ & $0.049(2)$ \\
\hline
\end{tabular}

Note: The k-range and R-range for the $k^{3}$-weighted Fe $K$-edge EXAFS are 2.5-10 $\AA^{-1}$ and 0-6 $\AA$, respectively. The potential is referenced to the RHE scale. 
Table S2. Operando ${ }^{57} \mathrm{Fe}$ Mössbauer parameters for ${ }^{57} \mathrm{Fe}$ enriched Fe-NC-S recorded at various applied biases in $\mathrm{CO}_{2}$-saturated $0.5 \mathrm{M} \mathrm{KHCO}_{3}$ solution.

\begin{tabular}{|c|c|c|c|c|c|c|}
\hline Component & & Assignment & $\begin{array}{c}\text { IS } \\
\left(\mathrm{mm} \mathrm{s}^{-1}\right)\end{array}$ & $\begin{array}{c}\text { QS } \\
\left(\mathrm{mm} \mathrm{s}^{-1}\right)\end{array}$ & $\begin{array}{c}\Gamma \\
\left(\mathrm{mm} \mathrm{s}^{-1}\right)\end{array}$ & $\begin{array}{r}\text { Area } \\
(\%)\end{array}$ \\
\hline \multirow{3}{*}{$\mathrm{OCV}$} & D1 & $\mathrm{Fe}^{\mathrm{II}} \mathrm{N}_{4}$, low spin & 0.36 & 0.73 & 0.55 & 63.9 \\
\hline & $\mathrm{D} 2$ & $\mathrm{Fe}^{\mathrm{II}} \mathrm{N}_{2+2}$, intermediate spin & 0.22 & 2.56 & 0.80 & 16.1 \\
\hline & D3 & $\mathrm{N}-\mathrm{Fe}^{\mathrm{II}} \mathrm{N}_{2+2}$, high spin & 0.77 & 2.43 & 1.08 & 20.0 \\
\hline \multirow{4}{*}{$\begin{array}{c}-0.3 \mathrm{~V} \\
(V s \mathrm{RHE})\end{array}$} & D1 & $\mathrm{Fe}^{\mathrm{II}} \mathrm{N}_{4}$, low spin & 0.35 & 0.67 & 0.50 & 49.2 \\
\hline & $\mathrm{D} 2$ & $\mathrm{Fe}^{\mathrm{II}} \mathrm{N}_{2+2}$, intermediate spin & 0.22 & 2.60 & 0.80 & 21.1 \\
\hline & D3 & $\mathrm{N}-\mathrm{Fe}^{\mathrm{II}} \mathrm{N}_{2+2}$, high spin & 0.77 & 2.75 & 1.08 & 21.1 \\
\hline & D4 & $\mathrm{CO}_{2}-\mathrm{Fe}^{\mathrm{I}} \mathrm{N}_{4}$, low spin & 0.41 & 1.40 & 0.47 & 8.6 \\
\hline \multirow{4}{*}{$\begin{array}{c}-0.6 \mathrm{~V} \\
(\mathrm{Vs} \mathrm{RHE})\end{array}$} & D1 & $\mathrm{Fe}^{\mathrm{II}} \mathrm{N}_{4}$, low spin & 0.36 & 0.63 & 0.47 & 44.6 \\
\hline & D2 & $\mathrm{Fe}^{\mathrm{II}} \mathrm{N}_{2+2}$, intermediate spin & 0.22 & 2.67 & 0.80 & 20.6 \\
\hline & D3 & $\mathrm{N}-\mathrm{Fe}^{\mathrm{II}} \mathrm{N}_{2+2}$, high spin & 0.77 & 3.04 & 1.08 & 23.9 \\
\hline & D4 & $\mathrm{CO}_{2}-\mathrm{Fe}^{\mathrm{I}} \mathrm{N}_{4}$, low spin & 0.40 & 1.40 & 0.47 & 11.0 \\
\hline \multirow{4}{*}{$\begin{array}{c}-0.9 \mathrm{~V} \\
(v s . \mathrm{RHE})\end{array}$} & D1 & $\mathrm{Fe}^{\mathrm{II}} \mathrm{N}_{4}$, low spin & 0.37 & 0.59 & 0.47 & 40.0 \\
\hline & $\mathrm{D} 2$ & $\mathrm{Fe}^{\mathrm{II}} \mathrm{N}_{2+2}$, intermediate spin & 0.22 & 2.90 & 0.80 & 17.2 \\
\hline & D3 & $\mathrm{N}-\mathrm{Fe}^{\mathrm{II}} \mathrm{N}_{2+2}$, high spin & 0.77 & 3.05 & 1.08 & 25.7 \\
\hline & D4 & $\mathrm{CO}_{2}-\mathrm{Fe}^{\mathrm{I}} \mathrm{N}_{4}$, low spin & 0.42 & 1.40 & 0.47 & 17.1 \\
\hline \multirow{3}{*}{ AFT } & D1 & $\mathrm{Fe}^{\mathrm{II}} \mathrm{N}_{4}$, low spin & 0.37 & 0.74 & 0.58 & 60.1 \\
\hline & D2 & $\mathrm{Fe}^{\mathrm{II}} \mathrm{N}_{2+2}$, intermediate spin & 0.22 & 2.66 & 0.80 & 18.3 \\
\hline & D3 & $\mathrm{N}-\mathrm{Fe}^{\mathrm{II}} \mathrm{N}_{2+2}$, high spin & 0.77 & 2.75 & 1.08 & 21.6 \\
\hline
\end{tabular}

Experimental errors are $\pm 0.02 \mathrm{~mm} \mathrm{~s}^{-1}$ for isomer shift (IS), $\pm 0.08 \mathrm{~mm} \mathrm{~s}^{-1}$ for quadrupole splitting (QS) and less than 3\% for relative area. IS is relative to $\alpha$-iron foil. 


\section{References}

1. Li, X.; Cao, C.-S.; Hung, S.-F.; Lu, Y.-R.; Cai, W.; Rykov, A. I.; Miao, S.; Xi, S.; Yang,

H.; Hu, Z.; Wang, J.; Zhao, J.; Alp, E. E.; Xu, W.; Chan, T.-S.; Chen, H.; Xiong, Q.; Xiao,

H.; Huang, Y.; Li, J.; Zhang, T.; Liu, B., Identification of the Electronic and Structural

Dynamics of Catalytic Centers in Single-Fe-Atom Material. Chem 2020, 6 (12), 3440-3454. 